\title{
Synthesis and Evaluation of Stearic Acid Derivatives as Cetane Number Improvers
}

\author{
Ambadas B. Rode, H. Thajudeen, Keunwoo Chung, ${ }^{\dagger}$ Young-Wun Kim, ${ }^{\dagger}$ and In Seok Hong ${ }^{\star}$ \\ Department of Chemistry, Kongju National University, Chungnam 314-701, Korea. ${ }^{*}$ E-mail: ishong@kongju.ac.kr \\ ${ }^{\dagger}$ Green Chemistry Research Division, Surfactant and Lubricant Research Team, KRICT, Daejeon 305-600, Korea \\ Received March 21, 2011, Accepted April 30, 2011
}

\begin{abstract}
1,2,4,5-tetraoxane, mono and dinitrate glycerol carbonate ester derivatives of stearic acid were synthesized along with the known 9(10)-keto methyl sterate, methoxy mono-nitrate and dinitrate of methyl stearate. Their cetane numbers $(\mathrm{CNs})$ were investigated to evaluate their viability for use as $\mathrm{CN}$ improvers. The $\mathrm{CN}$ performances of tetraoxane and all of the nitrate derivatives were investigated at 500 and $1000 \mathrm{ppm}$ concentrations and compared to that of a traditional $\mathrm{CN}$ improver 2-ethylhexyl nitrate (2-EHN). The experimental results suggest that all derivatives evaluated in this study showed better $\mathrm{CN}$ improvement than base diesel fuel. Specifically, the 1,2,4,5-tetraoxane derivative of stearic methyl ester was superior to all derivatives studied, also being superior to 2-EHN. We also discussed the correlations between the observed CN trends and thermo-analytical data resulted from thermo gravimetric analysis curves (TGA) and differential scanning calorimetry (DSC).
\end{abstract}

Key Words : Cetane number improver, Stearic acid derivative, Cyclic tetraoxane, 2-EHN

\section{Introduction}

The cetane number $(\mathrm{CN})$ measures the readiness of the fuel to auto-ignite when injected into an engine. It is one of the most important properties to specify the ignition quality of any fuel for internal combustion engines. An increase in $\mathrm{CN}$ decreases the delay time between fuel injection and ignition. Shorter ignition delay times have been directly correlated with a faster startup in cold weather, reduced $\mathrm{NO}_{\mathrm{x}}$ and particulate matter emissions from diesel engines, and smoother engine operation. ${ }^{1,2}$ The $\mathrm{CN}$ of a fuel depends on the composition and structure of the hydrocarbons present in the fuel. The $\mathrm{CN}$ decreases with an increase in the aromatic hydrocarbon content and increases with an increase in the $n$ paraffin and olefin content. ${ }^{3}$ The use of cetane-improving additives is necessary to avoid difficulties in cold starting and other performance problems associated with low CNs. Traditionally, alkyl nitrate (e.g. amyl nitrate, hexyl nitrate, and octyl nitrate) have been used as ignition promoters, but the use of azo compounds and alkyl peroxides has also been proposed. ${ }^{4,5}$

Biodiesel has been widely accepted as an alternative fuel additive. It can be blended up to $20 \%$ in any type of diesel engine. It is defined as alkyl esters of fatty acids, obtained by the transesterification of oils or fats with short-chain alcohols such as methanol and ethanol. It has engine performance capability comparable to that of conventional diesel and can be used pure or blended with diesel. ${ }^{6,7}$ The benefits of the fatty acid ester are likely related to its oxygen content and the long hydrocarbon chains of the fatty acids. The two oxygen molecules in the ester bond have the ability to improve combustion similar to the way oxygenates reduce carbon monoxide emissions for gasoline. ${ }^{8}$ Several studies showed a $\mathrm{CN}$ improvement through the use of fatty acid derivatives such as ester, ${ }^{9}$ nitrate, ${ }^{10,11}$ glycol nitrate, ${ }^{12}$ and tertiary fatty amides. ${ }^{13}$

Recently, we showed that 1,2,4,5-tetraoxane and 1,2, 4,5,7,8-hexaoxonane derivatives from cyclic and acyclic ketones with carbon numbers ranging from $\mathrm{C} 6$ to $\mathrm{C} 8$ were superior to traditional 2-ethyl hexyl nitrate (2-EHN) as a $\mathrm{CN}$ improver ${ }^{14}$ In this study, we attempt to extend our previous investigation of $\mathrm{CN}$ improvers to fatty acid derivatives which are now well-known biodiesel additives. We synthesized stearic methyl ester derivatives modified with 9(10)-1,2,4,5tetraoxane, 9(10)-methoxy-10(9)-nitrate and 9,10-dinitrate groups. Stearic glycerol carbonate ester derivatives with the 9(10)-methoxy-10(9)-nitrate and 9,10-dinitrate groups were also synthesized to evaluate the oxygen content effects as a $\mathrm{CN}$ improver. The $\mathrm{CN}$ performances of these derivatives were measured and compared with that of the traditional $\mathrm{CN}$ improver 2-EHN. We also discussed the correlations between the observed $\mathrm{CN}$ trends and thermo-analytical data resulted from the thermo gravimetric analysis curves (TGA) and differential scanning calorimetry (DSC).

\section{Experimental Section}

Materials and Methods. All of the starting chemicals were used as received from Sigma-Aldrich. 9(10)-keto methyl stearate (1) was synthesized from oleic acid according to a previously researched method ${ }^{15,16}$ followed by esterification. All solvents were purified using a standard procedure. Ultra low-sulfur diesel (ULSD) was received from the SK Corporation of Korea. The nuclear magnetic resonance (NMR) spectra were recorded on a Varian Mercury 400 spectrometer, with standard pulse sequences operating at $400 \mathrm{MHz}$ in ${ }^{1} \mathrm{H}-\mathrm{NMR}$ and at $100 \mathrm{MHz}$ in ${ }^{13} \mathrm{C}-\mathrm{NMR}$ in $\mathrm{CDCl}_{3}$ using tetramethylsilane (TMS) as an internal standard. The 


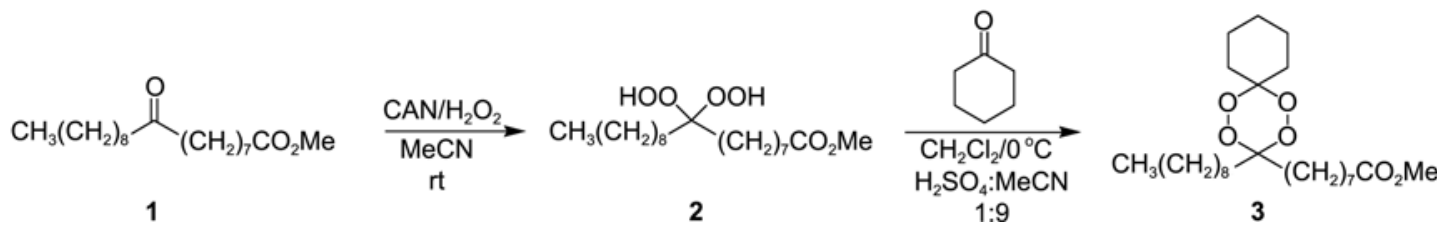

Scheme 1. Synthesis of 3-cyclohexyl-1,2,4,5 tetraoxane derivative of methyl stearate.

chemical shifts are given in parts per million (ppm). Mass determination of the final target molecules was conducted by electrospray ionization-mass spectrometry (ESI-MS). The derived cetane numbers (DCNs) of the tested fuel were determined on the basis of standards from the American Society for Testing and Materials (ASTM) D6890-2008. All $\mathrm{CN}$ measurements were performed by the Korea Institute of Petroleum Management.

Synthesis of 3-Cyclohexyl-1,2,4,5-tetraoxane Derivative of Methyl Stearate (3). The mixture of 9(10)-keto methyl stearate (1) was prepared by multistep synthesis from oleic acid as described in the literatures followed by esterification (Scheme 1). ${ }^{15,16}{ }^{1} \mathrm{H}-\mathrm{NMR}:\left(400 \mathrm{MHz}, \mathrm{CDCl}_{3}\right): \delta 0.86(\mathrm{t}$, $3 \mathrm{H}), 1.25-1.27(\mathrm{~m}, 18 \mathrm{H}), 1.52-1.55(\mathrm{~m}, 6 \mathrm{H}), 2.28(\mathrm{t}, 3 \mathrm{H})$, $2.36(\mathrm{t}, 3 \mathrm{H}), 3.65(\mathrm{~s}, 3 \mathrm{H}) ;{ }^{13} \mathrm{C}-\mathrm{NMR}:\left(100 \mathrm{MHz}, \mathrm{CDCl}_{3}\right): \delta$ $14.23,22.86,24.03,25.09,29.16,29.26,29.28,29.35$, $29.39,29.42,29.48,29.60,29.64,32.03,34.26,42.98$, 51.67, 174.48, 211.85; MS: calcd. $m / z, 312.487$, Obsd. $313.273[\mathrm{M}+\mathrm{H}]$.

9(10)-gem-dihydroperoxide methyl stearate 2 was synthesized as followed; a mixture of 9(10)-keto methyl stearate ( $1 \mathrm{mmol}), 50 \%$ aqueous $\mathrm{H}_{2} \mathrm{O}_{2}(1 \mathrm{~mL})$ and $\mathrm{CAN}(0.1 \mathrm{mmol})$ in $\mathrm{MeCN}(5 \mathrm{~mL})$ was stirred at room temperature for $6 \mathrm{~h}$. The reaction was quenched with water $(5 \mathrm{~mL})$ and the mixture was extracted with EtOAc $(3 \times 5 \mathrm{~mL})$. The combined organic extract was dried with anhydrous $\mathrm{Na}_{2} \mathrm{SO}_{4}$ and concentrated in vacuo. The crude product was purified by a silica gel column chromatography $(\mathrm{MeOH} / \mathrm{MC})$ to afford pure gem-dihydroperoxide 2. ${ }^{1} \mathrm{H}-\mathrm{NMR}$ : (400 $\left.\mathrm{MHz}, \mathrm{CDCl}_{3}\right)$ : $\delta 0.87(\mathrm{t}, 3 \mathrm{H}), 1.26-1.32(\mathrm{~m}, 21 \mathrm{H}), 1.60-1.67(\mathrm{~m}, 6 \mathrm{H}), 2.28-$ $2.33(\mathrm{t}, 3 \mathrm{H}), 3.67$ (s, 3H), 8.63 (br s, 2H). ${ }^{13} \mathrm{C}-\mathrm{NMR}$ : $(100$ $\left.\mathrm{MHz}, \mathrm{CDCl}_{3}\right): \delta 14.32,22.87,23.67,24.94,29.02-29.99$ (9 carbon peaks) overlapped, 32.07, 34.33, 51.89, 53.65, 114.16, 175.16.

3-Cyclohexyl-1,2,4,5-tetraoxane Derivative of Methyl Stearate 3: Cyclohexanone $(1.2 \mathrm{mmol})$ was added to a cooled solution (chilled via an ice bath) of gem-dihydroper- oxide $2(1 \mathrm{mmol})$ in $\mathrm{CH}_{2} \mathrm{Cl}_{2}(10 \mathrm{~mL})$. After the mixture was stirred for $30 \mathrm{~min}$ at a constant temperature, a cooled $\mathrm{H}_{2} \mathrm{SO}_{4} /$ $\mathrm{CH}_{3} \mathrm{CN}$ mixture [0.150 mL, 1:10 (v/v)] was added dropwise. After an additional $30 \mathrm{~min}$ of stirring, the reaction mixture was diluted with $\mathrm{CH}_{2} \mathrm{Cl}_{2}$ and washed with $\mathrm{H}_{2} \mathrm{O}(2 \times 10 \mathrm{~mL})$, saturated $\mathrm{NaHCO}_{3}(2 \times 15 \mathrm{~mL})$, and brine $(2 \times 15 \mathrm{~mL})$. The organic layer was dried with anhydrous $\mathrm{Na}_{2} \mathrm{SO}_{4}$ and concentrated in vacuo. The resultant crude was purified by column chromatography (silica gel, Hexane), yielding pure 3. ${ }^{1} \mathrm{H}-$ NMR: $\left(400 \mathrm{MHz}, \mathrm{CDCl}_{3}\right): \delta 0.84(\mathrm{t}, 3 \mathrm{H}), 1.20-1.27(\mathrm{~m}$, $22 \mathrm{H}), 1.42$ (br s, 3H ), 1.55-1.58 (m, 9H), 2.10-2.23 (m, 4H), $2.26(\mathrm{t}, 2 \mathrm{H}), 3.63(\mathrm{~s}, 3 \mathrm{H}) ;{ }^{13} \mathrm{C}-\mathrm{NMR}:\left(100 \mathrm{MHz}, \mathrm{CDCl}_{3}\right): \delta$ $14.23,14.39,22.11,22.79,22.80,25.54,29.16,29.24$, $29.27,29.34,29.44,29.51,29.64,29.70,29.83,29.92$, 32.02, 34.17, 34.20, 34.45, 51.53, 60.25, 107.88, 111.07, 174.34. MS: calcd. $m / z ; 442.329$, Obsd 465.319 [M+Na].

Synthesis of Nitrate Derivatives of Stearate Ester. Monoand di-nitrate derivatives of methyl stearate (4a and $\mathbf{4 b})$ were prepared according to the previously described method with a slight modification from methyl oleate by a sequential three-step method (Scheme 2). ${ }^{17-19}$

Synthesis of 10-Methoxy-9-nitrate Stearic Acid Glyceryl Carbonate Ester (5a): 10-Methoxy 9-nitrate stearic acid (2.4 g, $6.39 \mathrm{mmol})$ was dissolved in DMF and glycerol carbonate $(0.754 \mathrm{~g}, 6.39 \mathrm{mmol})$, EDC (1.34 g, $7.03 \mathrm{mmol})$, DMAP $(0.156 \mathrm{~g}, 1.27 \mathrm{mmol})$ were added at room temperature. After the completion of the reaction, the DMF was removed, and residues were washed with $\mathrm{NaHCO}_{3}$ and brine sequentially, and then dried with anhydrous $\mathrm{Na}_{2} \mathrm{SO}_{4}$. The crude product was purified by a silica gel column chromatography $(\mathrm{MeOH} / \mathrm{MC}=2: 98)$ to give glycerol carbonate ester (1.89 g, 62\% yield) as a yellow oil. ${ }^{1} \mathrm{H}-\mathrm{NMR}\left(\mathrm{CDCl}_{3}\right): 5.10$ $(\mathrm{m}, 1 \mathrm{H}), 4.93(\mathrm{~m}, 1 \mathrm{H}), 4.57(\mathrm{t}, 1 \mathrm{H}), 4.38-4.22(\mathrm{~m}, 3 \mathrm{H}), 3.40$ $(\mathrm{s}, 3 \mathrm{H}), 3.22(\mathrm{~m}, 1 \mathrm{H}), 2.38(\mathrm{t}, 2 \mathrm{H}), 1.67-1.28(\mathrm{~m}, 26 \mathrm{H}), 0.88$ (t, 3H); ${ }^{13} \mathrm{C}-\mathrm{NMR}: 173.36,154.56,84.73,81.25,73.97,66.17$, 63.06, 59.13, 34.06, 32.05, 29.43, 29.37, 29.31, 29.26, 29.13, $29.07,28.60,25.53,24.90,24.86,22.86,22.84,14.30 . \mathrm{MS}$ :

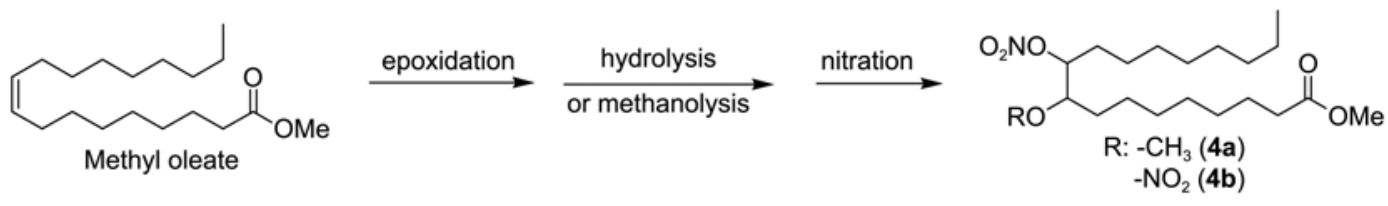

$$
\underset{\mathrm{MeOH}, \mathrm{rt}}{\stackrel{1 N \mathrm{NaOH}}{\longrightarrow}}
$$

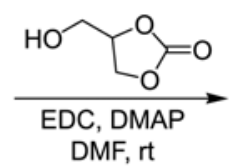

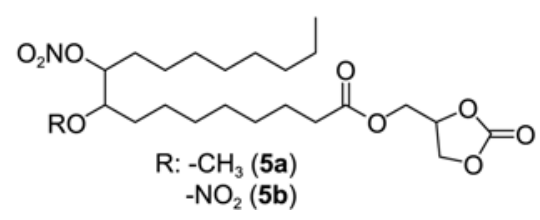

Scheme 2. Synthesis of nitrate derivatives of stearate ester. 
calcd. $m / z$; 475.278, Obsd 493.316 [M+NH4].

Synthesis of 9,10-Dinitrate Stearic Acid Glyceryl Carbonate Ester (5b): The 9,10-dinitrate stearic acid (2.5 g, 6.15 $\mathrm{mmol})$ was dissolved in DMF, and glycerol carbonate $(0.726$ $\mathrm{g}, 6.15 \mathrm{mmol}), \mathrm{EDC}(1.30 \mathrm{~g}, 6.76 \mathrm{mmol})$, DMAP $(0.150 \mathrm{~g}$, $1.23 \mathrm{mmol}$ ) were added at room temperature. After the completion of reaction, DMF was removed, and resulting residues were washed with $\mathrm{NaHCO}_{3}$ and brine, and then dried with anhydrous $\mathrm{Na}_{2} \mathrm{SO}_{4}$. The crude product was purified by a silica gel column chromatography (EtOAc/hexane $=20: 80)$ to give 9,10-dinitrate stearic acid glycerol carbonate ester $(2.19 \mathrm{~g}, 70 \%$ yield $)$ as a colorless oil. ${ }^{1} \mathrm{H}-\mathrm{NMR}$ $\left(\mathrm{CDCl}_{3}\right): 5.17(\mathrm{~m}, 2 \mathrm{H}), 4.91(\mathrm{~m}, 1 \mathrm{H}), 4.54(\mathrm{t}, 1 \mathrm{H}), 4.29(\mathrm{~m}$, $3 \mathrm{H}), 2.35(\mathrm{t}, 2 \mathrm{H}), 1.67-1.28(\mathrm{~m}, 26 \mathrm{H}), 0.85(\mathrm{t}, 3 \mathrm{H}) ;{ }^{13} \mathrm{C}-$ NMR: $173.30,154.61,82.05,82.01,74.00,66.17,63.07$, $34.00,31.96,29.42,29.40,29.29,29.27,29.13,29.01$, 28.96, 25.15, 25.05, 24.80, 22.81, 14.39, 14.27. MS: calcd. $\mathrm{m} / \mathrm{z} ; 506.247$, Obsd 524.286 [M+NH 4$]$.

Evaluation of CN Improvers. ULSD (SK Corporation) was used as a base diesel fuel. The efficacies of the cetane improvers were tested in 500-1000 ppm concentrations of additive in $1 \mathrm{~kg}$ of base fuel. The ignition properties of the diesel fuel formulations in this study were rated in terms of the DCNs of the formulations. The DCNs of the fuels were determined by the method described in ASTM D6890-2008.

Thermo-analytical Method of the Neat Additives. A TGA/DSC analysis was carried out to check the thermal stability and heat release property of all additives on a Setaram Labsys TG-DT/DSC instrument at scan rates of 5 ${ }^{\circ} \mathrm{C} / \mathrm{min}$ under a $\mathrm{N}_{2}$ purge of $100 \mathrm{~mL} / \mathrm{min}$. The amounts of loaded samples ranged from $5-10 \mathrm{mg}$ and the analysis temperature ranged from $50-600{ }^{\circ} \mathrm{C}$.

\section{Results and Discussion}

Cetane-Improving Performance of the Additives. The efficacies of the additives were determined as a DCN and they are summarized in Figure 1.

In this study, the DCN of the base diesel fuel was measured as 48.7. The $\triangle$ DCNs of the $\mathrm{y}$ axis was calculated by subtraction of the DCN of the base diesel fuel from the DCN of each additive. All of the tested derivatives showed a

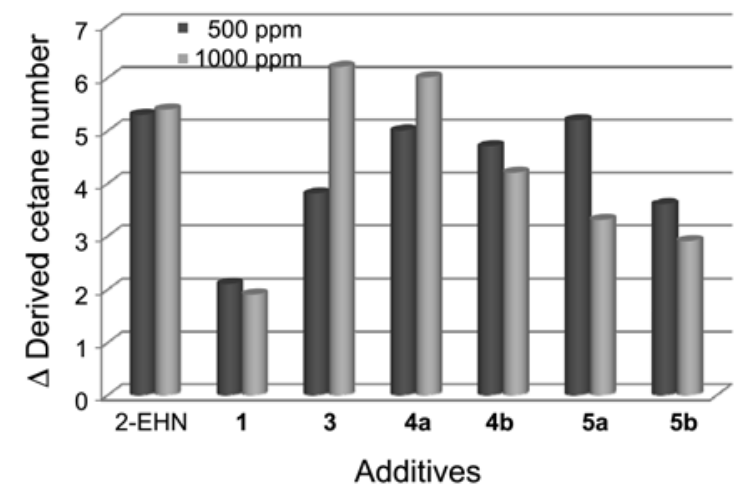

Figure 1. Cetane-improving performance of individual additives. $\triangle \mathrm{DCN}=\mathrm{DCN}$ of additives $-\mathrm{DCN}$ of base diesel fuel. higher DCN than that of the base diesel fuel. As shown in Figure 1, cyclic tetraoxane derivative $\mathbf{3}$ of methyl stearate $(1000 \mathrm{ppm})$ is more efficient than $\mathbf{1}$ and the nitrate derivatives $\mathbf{4 a}, \mathbf{4 b}, \mathbf{5 a}, \mathbf{5 b}$, and as well as the traditional $\mathrm{CN}$ improver 2-ethylhexyl nitrate (2-EHN). This is consistent with our previous studies, ${ }^{14}$ in which we suggested that the biradical intermediate produced from the thermal decomposition of tetraoxane or hexaoxonane, plays an important role in enhancing the chain reactions in the pre-ignition stage of diesel fuel combustion in diesel engines.

We expected an increase in $\mathrm{CN}$ with the increase in the additive concentration from 500 to $1000 \mathrm{ppm}$, but results showed an increase in $\mathrm{CN}$ of $\mathbf{3}$ and $\mathbf{4 a}$ and a decrease for $\mathbf{1}$, $\mathbf{4 b}, \mathbf{5} \mathbf{a}$ and $\mathbf{5 b}$. The reason for the decrease of the $\mathrm{CN}$ with the increase in the concentration is not clear. This type of nonlinearity was also reported for the blending cetane number. ${ }^{20}$

Previous studies have shown that glycerol carbonate oleate and stearate have good thermal and oxidation stability and exhibit good surfactant properties. ${ }^{21}$ Therefore, we envisaged that replacement of methyl in $\mathbf{4 a}$ and $\mathbf{4 b}$ with polyoxygenated (oxygen rich) glycerol carbonate will improve the $\mathrm{CN}$ efficiency as well as the stability of nitrate derivatives. Hence, we synthesized $\mathbf{5 a}$ and $\mathbf{5 b}$ and tested their $\mathrm{CN}$ performance levels. The $\mathrm{CN}$ measurement results showed that with the same number of backbone carbons, the $\mathrm{CN}$ of $\mathbf{5 a}$ at $500 \mathrm{ppm}$ is comparable to that of $\mathbf{4 a}$. However, at 1000 ppm the $\mathrm{CN}$ of $\mathbf{5 a}$ is significantly lower than that of $\mathbf{4 a}$. In the case of $\mathbf{5 b}$, the CNs at 500 and $1000 \mathrm{ppm}$ are lower than those of $\mathbf{4 b}$. These results suggest that the replacement of methyl ester with glycerol carbonate ester did not significantly improve the $\mathrm{CN}$ values.

Figure 1 and the results in Table 1 shows that there is no connection between the oxygen or nitrogen contents of an individual additive and the DCN; e.g., $\mathbf{5 a}$ and $\mathbf{5 b}$ derivatives have higher oxygen content levels by 30.3 and 34.7 over the $\mathbf{4 a}$ and $\mathbf{4 b}$ derivatives, respectively. However, they show poor $\mathrm{CN}$ performance.

Correlation between the DCNs and the TGA/DSC Data for Neat Additives. Mc Donnell et al. used the volatilization temperature as determined from TGA and DSC to estimate the possible behavior of fuels in the combustion chamber of a diesel engine. ${ }^{22}$ To investigate the possible combustion behavior of the aforementioned additives in an

Table 1. Appearance of the target molecules, and their calculated oxygen/nitrogen contents

\begin{tabular}{cccc}
\hline Product entry & $\begin{array}{c}\text { Oxygen contents } \\
(\%)\end{array}$ & $\begin{array}{c}\text { Nitrogen } \\
\text { contents (\%) }\end{array}$ & Appearance \\
\hline 2-EHN & 27.4 & 8.0 & white liquid \\
$\mathbf{1}$ & 15.4 & 0 & white solid \\
$\mathbf{3}$ & 21.7 & 0 & colorless oil \\
$\mathbf{4 a}$ & 25.6 & 3.7 & yellow oil \\
$\mathbf{4 b}$ & 31.5 & 6.9 & yellow oil \\
$\mathbf{5 a}$ & 30.3 & 2.9 & yellow oil \\
$\mathbf{5 b}$ & 34.7 & 5.5 & yellow oil \\
\hline
\end{tabular}




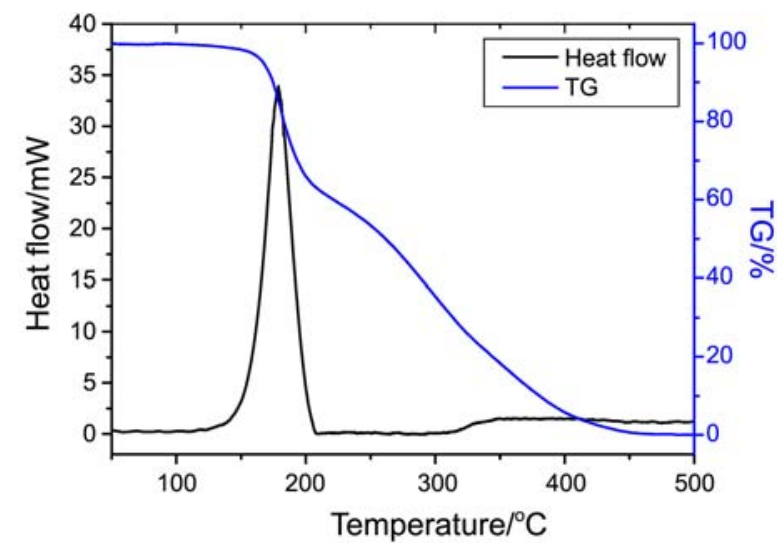

Figure 2. TGA and DSC graph of 1,2,4,5-tetraoxane derivative 3.

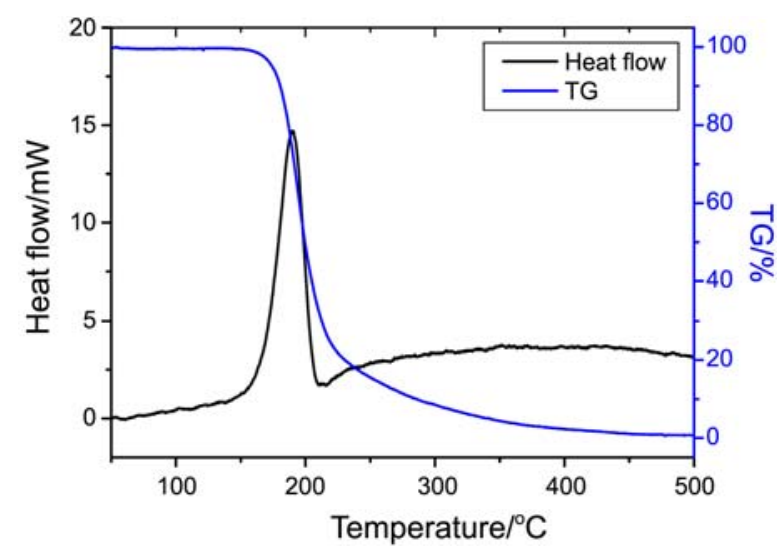

Figure 3. TGA and DSC graph of methyl stearate mono-nitrate derivative $\mathbf{4 a}$.

engine, we performed a TGA/DSC analysis. For the TGA/ DSC analysis, neat samples of the additives were exposed to heat under a $\mathrm{N}_{2}$ atmosphere at a constant heating rate of $5{ }^{\circ} \mathrm{C} / \mathrm{min}$. Two representatives TGA/DSC curves of compounds 3 and 4a are shown in Figures 2 and 3, respectively. The data for the remaining samples are summarized in Table 2.

As show in Table 2, all of the DSC curves of the neat samples exhibit exothermic peaks except compound 1, which showed an endothermic peak. The exothermic peaks of compounds $3, \mathbf{4 a}, \mathbf{4 b}, \mathbf{5 a}$, and $5 \mathbf{b}$ and the endothermic peak of $\mathbf{1}$ are the results from the decomposition and the evaporation process, respectively. Our TGA/DSC analysis

Table 2. Exothermic temperature, heat release and loss of weight from TGA/DSC data for neat additives

\begin{tabular}{cccc}
\hline Compounds & $\begin{array}{c}\text { Exotherm peak } \\
\left({ }^{\circ} \mathrm{C}\right)^{a}\end{array}$ & $\begin{array}{c}\text { Peak area } \\
(\mathrm{J} / \mathrm{g})^{a}\end{array}$ & $\begin{array}{c}\text { Loss of weight } \\
(\%)^{b}\end{array}$ \\
\hline $\mathbf{1}$ & 293.67 & +96.89 & 100 \\
$\mathbf{3}$ & 178.82 & -1034.45 & 33 \\
$\mathbf{4 a}$ & 187.17 & -386.15 & 67 \\
$\mathbf{4 b}$ & 183.45 & -1292.75 & 56 \\
$\mathbf{5 a}$ & 192.96 & -373.63 & 35 \\
$\mathbf{5 b}$ & 187.59 & -1080.30 & 35 \\
\hline
\end{tabular}

${ }^{a}$ From DSC data. ${ }^{b}$ Loss of weight during exothermic reactions

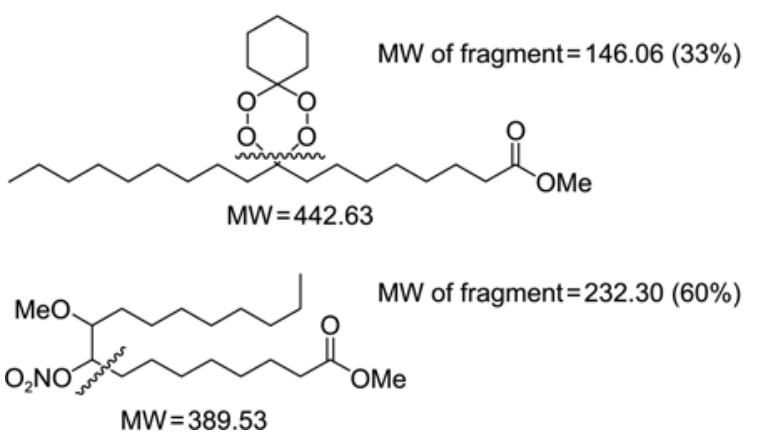

Figure 4. Loss in weight (\%) for 1,2,4,5-tetraoxane and mononitrate derivatives during the exothermic reaction

results (Table 2) provide a useful explanation of the $\mathrm{CN}$ trend shown in Figure 1. According to the decomposition peaks of the pure samples, the decomposition temperatures of the samples are in the order of 9(10)-keto methyl stearate (1) $>$ nitrate carbonate ester derivatives $(\mathbf{5 a}, \mathbf{5 b})>$ nitrate methyl ester derivatives $(\mathbf{4 a}, \mathbf{4} \mathbf{b})>1,2,4,5$-tetraoxne derivative (3), implying that the nitrate and tetraoxane functionalities make the stearic acid molecules more ignitable. Among these additives, 1,2,4,5-tetraoxne derivative (3) has a lower decomposition temperature, showing a $33 \%$ weight loss during the exothermic process, which is related to cyclohexyl peroxide fragmentation. Similarly, mono-nitrate derivative (4a) showed a $67 \%$ loss during the decomposition process, which is related to the cleavage of the alpha bond near the nitrate functionality, as shown in Figure 4.

During the TGA/DSC data analysis, we noted a correlation between the decomposition temperatures and the derived cetane number: 1,2,4,5-tetraoxne derivative (3) with a lower decomposition temperature having a higher DCN and nitrate derivatives with a higher decomposition temperature having a relatively low DCN. Table 4 shows the amount of heat release during the exothermic process as calculated from the DSC data; however, no direct relationship with a DCN trend can be observed.

\section{Conclusion}

1,2,4,5-Tetraoxane, mono and dinitrate glycerol carbonate ester derivatives of stearic acid were synthesized along with known 9(10)-keto and methoxy mono-nitrate and dinitrate of methyl stearate, respectively, and their cetane numbers were measured. All tetraoxane and nitrate derivatives evaluated in this study showed a $\mathrm{CN}$ improvement over the base diesel fuel. The 1,2,4,5-tetraoxne derivative (3) and the mono-nitrate derivative (4a) of stearic acid methyl ester showed greater efficacy than the traditional nitrate additive 2-EHN at $1000 \mathrm{ppm}$. The replacement of methyl ester with polyoxygenated glycerol carbonate had a negative impact on the $\mathrm{CN}$ values. The 1,2,4,5-tetraoxne derivative (3) was found to be superior among all of the studied derivatives. Furthermore, we discussed the correlations between the observed $\mathrm{CN}$ trends and thermo-analytical data resulted from the thermo gravimetric analysis curves (TGA) and 
differential scanning calorimetry (DSC).

Acknowledgments. This research was supported by a grant from the Fundamental R\&D Program for Core Technology of Materials funded by the Ministry of Knowledge Economy, Republic of Korea.

\section{References}

1. Suppes, G. J.; Goff, M.; Burkhart, M. L.; Bockwinkel, K. Energy Fuels 2001, 15, 151.

2. McCormick, R. L.; Graboski, M. S.; Alleman, T. L.; Herring, A. M.; Tyson, K. S. Environ. Sci. Technol. 2001, 35, 1742.

3. Zinenko, S. A.; Egorov, S. A.; Makarov, A. A.; Sharin, E. A.; Manaenkov, V. M.; Bakaleinik, A. M. Chem. Technol. Fuels Oils 2002, 38, 303.

4. Danilov, A. M. Chem. Technol. Fuels Oils 2001, 37, 444.

5. Schabron, J. F.; Fuller, M. P. Anal. Chem. 1982, 54, 2599.

6. Pinto, A. C.; Guarieiro, L. L. N.; Rezende, M. J. C.; Ribeiro, N. M.; Torres, E. A.; Lopes, W. A.; Pereira, P. A. P.; De Andrade, J. B. J. Braz. Chem. Soc. 2005, 16, 1313.

7. Pimentel, M. F.; Ribeiro, G. M. G. S.; Cruz, R. S.; Stragevitch, L.; Pacheco Filho, J. G. A.; Teixeira, L. S. G. Microchem. J. 2006, 82, 201.

8. Downstream Alternatives Inc. Changes in gasoline III. Bremen,
IN, 1996.

9. Knothe, G.; Matheaus, A. C.; Ryan, T. W. Fuel 2003, 82, 971.

10. Suppes, G. J.; Dasari, M. A. Ind. Eng. Chem. Res. 2003, $42,5042$.

11. Proirier, M. A.; Steere, D. E.; Krogh, J. A. US Patent 5454842, 1995.

12. Suppes, G. J.; Chen, Z.; Rui, Y.; Mason, M.; Heppert, J. A. Fuel 1999, 78, 73 .

13. Serdari, A.; Lois, E.; Stournas, S. Int. J. Energy Res. 2000, 24, 455 .

14. Rode, A. B.; Chung, K.; Kim, Y. W.; Hong, I. S. Energy \& Fuels 2010, 24, 2636.

15. Khan, N. A.; Deatherage, F. E.; Brown, J. B. Organic Syntheses $1963,4,851$.

16. Myddleton, W. W.; Barrett, A. W. J. Am. Chem. Soc. 1927, 49, 2258.

17. Suppes, G. J.; Dasari, M. A. Ind. Eng. Chem. Res. 2003, 42, 5042.

18. Suppes, G.J.; Goff, M.; Burkhart, M. L.; Bockwinkel, K. Energy \& Fuels 2001, 15, 151 .

19. Gruber, W.; Machemer, H.; US Patent 2332849, 1943.

20. Murphy, M. J.; Taylor, J. D.; McCormick, R. L. Compendium of experimental cetane number data. National Renewable Energy Laboratory, subcontractor report, 2004, SR- 540-36805.

21. Mouloungui, Z.; Pelet, S. Eur. J. Lipid Sci. Technol. 2001, 103, 216.

22. Mc Donnell, K.; Ward, S.; Leahy, J. J.; McNulty, P. JAOCS 1999, $76,539$. 